\title{
Everyone's a critic
}

\section{Scientific flaws in a film can distract the most avid filmgoer and lend fodder to countless blog posts. But how do filmmakers actually check their facts - and how much should we really care?}

Fridge logic is Alfred Hitchcock's trope for a plot inconsistency that "hits you after you've gone home and start pulling cold chicken out of the icebox." But all too often, cinematic logic fails in real time while you're still in your seat. And none more so, perhaps, than that bred of bad science (or implausible scientists). Fortunately - for the pedantic among us, and for Hollywood - there are scientists adept at coaching filmmakers to get it right.

Science consulting in Hollywood is still regarded as something of a cottage industry. Caltech particle physicist Sean Carroll notes that, when it comes to science, the level of interest varies with the filmmaker. "The scientist", he jokes, "is often valued less than the person who buys snacks for the actors."

Consulting on a film can range from an hour or two over a single afternoon, to recurrent meetings and phone calls over weeks and months. And the remuneration is not set. Unlike the scientists paid to make sure Disney's water looks wet, those consulted - but not relied on - often go unpaid. Likewise, the timing can vary: scientists can help with the development of the script or weigh in only after filming has commenced.

Conversely, in television, the consultant often has an ongoing dialogue with the creative team. It's primarily for this reason that planetary physicist Kevin Grazier prefers working in television. Author of the Hollyweird Science series and consultant on projects as varied as Battlestar Galactica and Gravity, Grazier values the sense of continuity television affords. "You have a long-term relationship with that production," he says, "and there is more of an inclusive sense of teamwork in television."

But continuous engagement with a project like a television show can carry with it a large degree of responsibility. UCLA's David Saltzberg, who consults on The Big Bang Theory, is the last word on the show's scientific content. "If a scientific error gets through," he says, "the blame is on me". And he's humble when it comes to recognizing the talents of his collaborators. "My job is simple. I just need to say what is true. The writers have the hard part of creating a story out of nothing."

In his book, Lab Coats in Hollywood, University of Manchester science communication expert David Kirby dubs this "entertainment expertise", and notes that the most productive collaborations between scientists and filmmakers occur when each recognizes the other's strengths. Carroll is suitably pragmatic about his role, and can forgive "bendings of the laws of nature that serve a purpose for the story", as long as they don't simply spring from lazy writing.

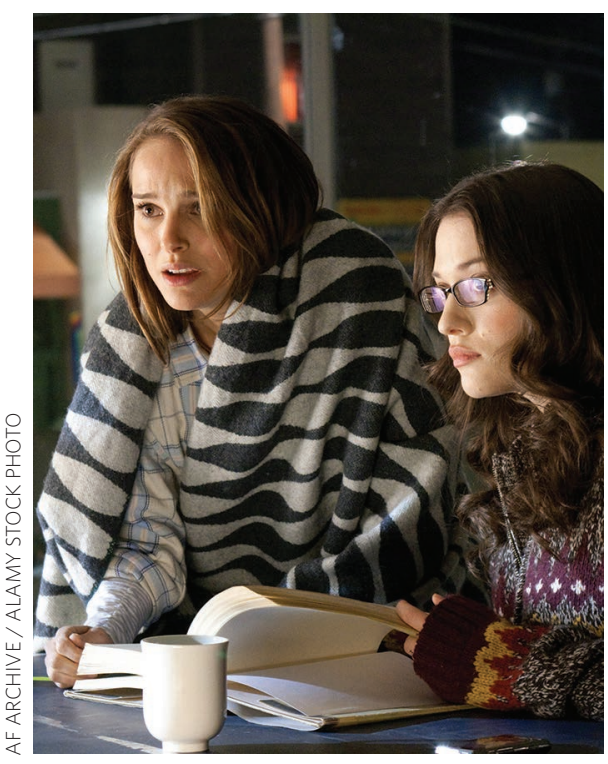

This flexibility comes hard won, after a number of years collaborating with the entertainment industry. He recalls a meeting with an actor appearing as a theoretical physicist in the upcoming film Inversion. A group of his graduate students, all new to the world of consulting, responded with a kneejerk 'no' to all of her ideas.

Carroll's suggestion was that they take the plot of the movie as data rather than theory. "It's happening", he told them. "Your job as a theoretical physicist is to explain it." Their response was a host of creative solutions that moved the collaboration forward, turning it into a problem-solving exercise rather than a copy-editing task. As Carroll points out, "the number of things that can happen that are compatible with the current laws of physics is surprisingly large."

James Kakalios, a condensed-matter physicist at the University of Minnesota, has a similar take: he sees his role in consulting for films like The Amazing Spider-Man as helping to reinforce the reality that the filmmaker is trying to create. "We ignore the effect of friction and air resistance in a first-year physics problem", he says. In the same way, if someone is strong enough to lift a building over their head, "we're not going to worry about the details of how they are that strong. We'll address the question of whether the building will crumble under its own weight." Enough detail to suspend disbelief, but not to destroy the filmmaker's vision.

Kakalios recognizes an opportunity for scientific outreach in his work for film and television. "Take something that people are already interested in," he says, "and the hope is that they'll realize the value of physics research in their everyday lives." This aim is one of many that led to the formation of the National Academy of Science's Science \& Entertainment Exchange, through which many scientists now consult on a volunteer basis. It introduced Carroll to the people behind Thor - a collaboration that saw Natalie Portman's Jane Foster (pictured) morph from comic-book nurse into silverscreen particle physicist.

The Exchange was also responsible for teaming Kakalios up with the makers of Watchmen, after he created a stir with his lecture series 'Everything I Know About Physics I Learned from Reading Comic Books', which led to his first book The Physics of Superheroes. Part of his motivation for the series came from a sense of the inaccessibility of mass media coverage of science.

"Whenever there's a big scientific discovery," he says, "it tends to be something that's truly revolutionary, but divorced from people's lives." The advances that affect the everyday dwell in the seldom-reported materials science and condensed-matter physics results. "One way to make that connection", says Kakalios, "is through television and film."

Whether or not that's wishful thinking, it's clear there's value in having authentic portrayals of science and scientists in film and television - the world could use a few more Jane Fosters. And as Saltzberg points out: "At a minimum there are young people out there who learn that one can have a life in science."

See the book review by Nina Meinzer and Ross Cloney on page 107 for more on the details of science in film. 